an appendix in Mr. de Selincourt's recent collation of the editions of the "Guide," Wordsworth assumes that every person of taste would prefer that the whole garden should be as near to Nature as possible, and pays no regard to the circumstance that in the im. mediate vicinity of the mansion it is permissible to prefer formal lines on account of their harmony with those of architecture. Thus, although Wordsworth may have been in advance of his time as an advocate of the free play of the senses, he did not go so far as we now know to be desirable.

Mr. de Selincourt has included as a second appendix letters to the Morning Post written by Wordsworth in 1844 on the subject of the proposed Kendal and Windermere Railway. Descending to the dusty arena of practical affairs, his academic mind loses something of its lofty detachment. It is interesting to compare these letters with a recent work entitled " England and the Octopus," dealing with the things that to-day impair the peacefulness of our scenery. The style of Wordsworth is indeed less trenchant than that of Mr. Clough Williams-Ellis, but underlying exasperation is almost equally evident. On the whole, however, it is when Wordsworth is dealing with general principles that he is of most service to the cause which so many of us have at heart, the preservation of scenic beauty, and we may well take the concluding paragraph of his "Description" as the text of our present appeal for preservation of scenic amenity in the countryside generally and the district of the English Lakes in particular :

"It is then much to be wished that a better taste should prevail among these new proprietors; and, as they cannot be expected to leave things to themselves, that skill and knowledge should prevent unnecessary deviations from that path of simplicity and beauty along which, without design and unconsciously, their humble predecessors have moved. In this wish the author will be joined by persons of pure taste throughout the whole island, who, by their visits (often repeated) to the Lakes in the North of England, testify that they deem the district a sort of national property, in which every man has a right and interest who has an eye to perceive and a heart to enjoy."

\title{
Jubilee Congress of the Folk-lore Society.
}

THE Jubilee Congress of the Folk-lore Society was held, as previously announced, on Sept. 19-25 in London, the president being the veteran scholar, Lieut.-Col. Sir Richard C. Temple. With the exception of one session on the evening of Sept. 20, which was held at the Imperial Institute, the meetings were held in the rooms of the Society of Antiquaries, which had been placed at the disposal of the congress by the Council of that body.

The congress, though small in numbers, was distinguished in its membership, and a number of prominent folk-lorists from abroad were present, mostly representing continental or American bodies. Among them were Dr. Fritz Boehm, of Berlin, representing the Vereins für Volkerkunde; Dr. Gudmund Schütte, of Sweden; Miss A. W. Beckwith, representing the Folk-lore Foundation of Vassar College, N.Y.; Dr. Marcu Beza, of the Rumanian Academy; Prof. Y. M. Goblet, of the Société Ernest Renan, Paris ; Prof. R. Pettazoni, of the Universities of Rome and Bologna; and Dr. Rütimeyer, of the Schweitzer Gesellschaft für Volkerkunde. A number of British societies were also officially represented.

It may not be inopportune to recall that when the Folk-lore Society was founded in 1878 by a small band of enthusiasts, among whom the late William J. Thoms and the late Mr. (afterwards Sir) Laurence Gomme were the leading spirits, the subject of its study had hardly won a generally recognised name. There would also seem to have been no very precise agreement as to its exact object and scope. So much so that, even in a leaflet published on behalf of the Society some years later, it was felt necessary to explain in what respects the science of folk-lore differed and was distinguishable from other studies with which it was in danger of being confused. The reason for this, of course, was that the Society had not confined itself to the study of survivals among civilised populations and the collection of folk-tales, but had included the study of certain aspects of 'savage' culture within its scope, and might, therefore, have been thought to be encroaching too broadly upon the province of ethnography.

On many occasions Sir Laurence Gomme in his writings, and notably before the Anthropological Section of the British Association, endeavoured to lay down the line of demarcation of his studies. Although the lines may have been overstepped, in general and as a matter of practice the Society's field of operations has been well marked out. Its original aim was two-fold: the collection of the customs, beliefs, sayings, etc., of the folk, and secondly, the classification, comparison, and interpretation of the matter thus collected. A valuable handbook for collectors was prepared which has been revised as the development of the study has required, and the work of the Society has been recorded in a journal which has been supplemented by the publication of supplementary volumes, either original studies too lengthy for inclusion in the journal or reprints of ' classics' of folk-lore almost unobtainable in their original or indeed in any form.

It is worth while to recall these facts in connexion with this congress, for it cannot but be felt that the Society and the study it represents are not receiving in this jubilee year the support from the public which they deserve. The study of folk-lore was taken up with some vigour on the Continent, where the term, first used by W. J. Thoms and adopted in England to distinguish the subject, was accepted as the official designation of the study of the culture of the people.

The recognition that is now accorded such studies on the Continent is indicated by a communication presented to the congress by Dr. Fritz Boehm, in which he surveyed the academic position of folklore in Germany. In Prussia folk-lore, since the educational reform of 1925 , is being introduced into the curricula of the elementary school, the secondary school, and the university, and other States will probably follow this example. In fact, it is represented in some form or other in most German universities. Yet Dr. Boehm lamented the fact that Germany is behind Scandinavia in this respect, as was in part borne out by Dr. A. Cyriax's account of the study of folk-lore and art in Sweden and the museums devoted to it. While this is not the occasion to enlarge upon such reflections as this contrast with conditions in Great Britain may suggest, it is perhaps worth while to point out that, though the important work of collection must not be neglected now that the material is disappearing more rapidly than ever in the stress of modern life, too little attention may be given to the work of analysis, synthesis, and comparison which gives meaning to the isolated facts and keeps alive the interest of an intelligent but uninstructed public.

Turning to the proceedings of the congress, it is gratifying to observe that so far as the number and

No. 3075, VoL. 122] 
quality of the papers was concerned the congress was a success. The meetings were well attended and the papers followed with close attention, even in those few cases in which the authors were not able to attend in person.

The president, Sir Richard Temple, a contributor to the proceedings of the Society almost from its inception, in his address on "The Mystery of Mental Atmosphere," dealt with a topic of no little philosophic import. He sought the origin of magic in the attempt of the primitive mind to bridge the gap that philosopher and savage alike reach at the point which is beyond experience and passes understanding. Recalling an observation of his own on a voyage to Rangoon, which revealed to him that a personage, al-Khidr, had been identified among the people with almost every hero of the past and many smaller local ones, he argued that such beings as this represent to the populace the unknown and mysterious by which they endeavour to bridge the gap, while the mind, clinging, as Andrew Lang suggested, to whatever it absorbs, modifies it, and by each contact produces an atmosphere which overlaps but never destroys those produced by previous contacts. Folklore, therefore, to be scientific in studying any given belief, should ascertain the mental atmosphere at the time of absorption of the people who had absorbed it.

The proceedings of the congress covered a wide range, both geographically and in subject matter. One of the most striking papers in its choice of subject was a study of stone-carrying women, by Mrs. Banks, who has followed up the persistent story in western Europe of women who dropped stones from creels on their shoulders or from their aprons, among whom even the Virgin Mary found a place. She sought to connect the legend with the clearing of land by women as early agriculturists.

Several contributors offered papers on extraEuropean folk-lore. Prof. Sayce, who was one of the original members of Council of the Society, dealt with Egyptian folk-lore, as did Miss Blackman in its medical aspect; Mrs. Spoer (Miss Goodrich-Freer) with Hebrew amulets; Capt. M. W. Hilton-Simpson with medical magic in Algeria. Prof. Starr sent a communication on Filipino magic, and Mr. R. E. Enthoven described beliefs connected with tree and animal worship in India, and showed the identity in the conception of tree, animal, and human soul.

Among papers dealing with the Near East were Prof. R. M. Dawkins on the study of folk-lore in modern Greece, and an interesting account of mummers' plays in Attica by Prof. H. J. Rose. Mrs. Hasluck described " the most primitive people in Europe outside Russia" - the Sarakachan people, who spend the summer in the Pindus mountains and the winter in the plains of Macedonia. She has visited two branches of these people, one the Albanian Vlacks, and the Sarakachan peoples proper, who, curiously enough, owing to local conditions. have reverted from a settled to a nomadic life. Dr. Beza gave the congress a view of Rumanian folk-lore in his account of the work of Demetrius Contemir's contribution to folk-lore, and Prof. Gudmund Schütte dealt ably with the evidence for the worship of the bull among the Kimbri. In the evening session at the Imperial Institute, Prof. Pospisil, of Brno, gave an account illustrated by a kinematograph film of the folk dances and customs of Central Europe.

British folk-lore was well represented, and offered one of the most interesting of the papers presented at the congress in an account of witchcraft in Wales, of which perhaps the most striking feature was the extent to which the belief is still prevalent among the educated. A witch has been considered a more efficacious thief-finder than a policeman, and a piece of moleskin worn on the chest of more avail than a doctor. The use of written charms in English suggests an English origin for some forms of the belief. Mr. T. W. Thompson's interesting account of British gypsy marriage and divorce customs included references to the eating of the blood-cake and the jumping of the bride and bridegroom over a branch of flowering broom or a besom made of broom. A paper was presented on behalf of Canon MacCulloch discussing aspects of the Arthurian legend, and Miss Mona Douglas gave an account of various beliefs relating to animals in Manx folk-lore, according to which cows were held most susceptible to witchcraft, and the witch was believed to take the form of a hare. Miss B. C. Spooner described 'charming' in Cornwall, the counterpart of the modern faith-healing. A suggestive paper by Prof. Pettazzoni on confession among primitive people, described the confessional as an analogue of the expulsion of sin or disease by washing or drawing of blood, the evil being expelled by verbal enunciation.

A fitting climax to the prominence of witchcraft in the proceedings of the congress was a communication from M. P. Saintyves, which was read by M. Goblet, on the 'witches' sabbath,' in which the author maintained the existence of a magic religion and secret church of wizards in the Middle Ages.

The programme on the concluding day included papers on the psycho-analytic side of folk-lore. Dr. Ernest Jones, in dealing with the question generally, made special reference to the significance of beliefs relating to the number three. Dr. Roheim dealt with "Mother Earth and the Children of the Sun."

The social side of the congress was not neglected. It opened with a presentation of the delegates to the president by Prof. J. L. Myres, and the members were entertained by Dr. Henry Wellcome at the Historical Medical Museum, and by Mr. and Miss Canziani. Visits were paid to Oxford and Cambridge; the English Folk Dance Society gave a demonstration of folk-dances, folk-songs, and children's singing games; and an official dinner was held on the concluding day.

\section{Energy and Atoms.}

A MESSEL memorial address, entitled "Available A Energy," was delivered by Prof. R. A. Millikan on Sept. 5 in New York at a joint meeting of representatives of the British Society of Chemical Industry and the Institution of Chemical Engineers with the American Institute of Chemical Engineers. As might be expected from Prof. Millikan's recent researches, his treatment of his subject proceeded upon somewhat unorthodox lines, and in the greater part of his lecture he was concerned with astronomical problems, rather than with the physical and engineering thermo.

No. 3075, Vor. 122] dynamics suggested by his title. The apology he made for offering an apparently abstract subject of this nature to a technical audience was the fact, perhaps usually insufficiently appreciated, that many of the distinctive features of modern civilisation come from our present knowledge of mechanics, which, in turn, was largely developed through the pioneer work done in the seventeenth and eighteenth centuries upon extra-terrestrial problems.

The fundamental work of Prof. Millikan and Dr. Cameron themselves upon the cosmic rays is by now 